\title{
Fanti S, Farsad M, Mansi L (eds): PET-CT Beyond FDG: a Quick Guide to Image Interpretation (1st edition)
}

\author{
Springer, Berlin 2010, ISBN: 978-3-540-93908
}

\author{
Giovanna Pepe • Arturo Chiti
}

Published online: 30 June 2010

(C) Springer-Verlag 2010

The introduction of FDG PET/CT has been a milestone in diagnostic imaging, though further investigation in cellular metabolism has led to the explorration of new frontiers of molecular imaging and to the development of novel tracers for $\mathrm{PET} / \mathrm{CT}$.

Therefore, after the wide success of their previous Atlas of PET-CT: a Quick Guide to Image Interpretation, the authors are now aiming to guide us on a journey through non-FDG PET tracers.

The atlas currently reviewed keeps a fresh though incisive approach to different PET/CT tracers that are gaining interest in routine clinical practice, such as ${ }^{18} \mathrm{~F}$ or ${ }^{11} \mathrm{C}$-choline and ${ }^{11} \mathrm{C}$-methionine, and research, such as radiopharmaceuticals for hypoxia or hormonal receptors.

The book is organized into 15 chapters. The first chapter is an introduction to this new challenging world of tracers other than FDG. The authors clearly explain the need for a "strategy tailored for each patient" to answer more questions about prognosis and therapy, thanks to a wider range of information about the disease status. After an excursus on the major PET isotopes in the second chapter, each of the following 12 chapters analyses a specific non-FDG tracer. Physiological bio- distribution, with normal uptake and excretion, is well explained not only with simple and smart descriptions but also with high-quality illustrations. The atlas is structured as a visual guide to normal and pathological findings; pearls and pitfalls are described and tracer characteristics are shown through clinical cases and often further explained with the comparison of findings from other imaging techniques.

Finally, Chapter 15 is not just a bibliography but a little treasure of references for readings about each tracer previously analysed.

This user-friendly atlas is not only helpful for young nuclear medicine physicians getting acquainted with new tracers, but also for more experienced colleagues needing a reference or searching for a focused analysis of non-FDG tracers.

In answer to all those thinking that a book is always already old when published, this atlas is an example of how a little book can constitute not just a guide to what is already there but also a "hint" to new knowledge. It offers useful background to build up the "personal atlas" of professional experience: a book that should be available in university libraries and reporting rooms.

G. Pepe $\cdot$ A. Chiti $(\bowtie)$

Rozzano, Italy

e-mail: arturo.chiti@humanitas.it 